administration was the largest source of extra fluid and sodium, with a mean (SD) contribution of 4.4 $(2 \cdot 6) \mathrm{ml} / \mathrm{kg} /$ day of fluid and $0 \cdot 68(0 \cdot 61) \mathrm{mmol} / \mathrm{kg} /$ day of sodium during the five day period in infants weighing less than $1000 \mathrm{~g}$ at birth.

The absolute amount of fluid and sodium gained from the three hidden sources was similar in all infants regardless of body weight, but when normalised for body weight the contribution from the three hidden sources was less significant in larger infants.

\section{Discussion}

Newborns undergoing intensive care gain significant amounts of fluid and sodium from drugs, bronchial lavage, and flushing of catheters-sources that are not normally taken into account when calculating the daily requirement. The proportion of extra fluid gained depends very much on the weight of the infant, peaking at a mean of $12 \mathrm{ml} / \mathrm{kg} /$ day in infants aged 3 days weighing less than $1000 \mathrm{~g}$ at birth. The amount of extra fluid gained in larger infants was probably not clinically significant in our study group but might have been significant in an infant in severe renal failure. The largest source of 'hidden' fluid was drugs, and this should lead to a reappraisal of the dilutions used, and in particular of whether it is necessary to flush the intravenous catheter before and after injecting each drug. Similarly, to flush an arterial catheter it should not be necessary to do more than replace the volume of blood sampled.

We were surprised at how much extra sodium could be gained from these 'hidden' sources. It was not our normal policy to prescribe sodium in the first two to three days of life, yet the mean gain in sodium from these sources in the first five days of life was $1.6 \mathrm{mmol} / \mathrm{kg} /$ day in the infants weighing less than $1000 \mathrm{~g}$ at birth. The largest source for 'hidden' sodium was the administration of drugs. Once again it was the saline used in flushing the intravenous line before and after the administration of each drug that contributed most.

A significant proportion of the fluid and sodium intake of infants in intensive care comes from sources that are not normally recorded. Frequent reappraisal of the fluid requirements will tend to minimise the clinical significance of the 'hidden' fluid intake, except in infants with severe renal failure. The sodium load from these hidden sources, however, may be much more important, as excessive intake might not be obvious clinically but could result in fluid retention. Clinicians involved in neonatal intensive care should be aware of these hidden sources of sodium and fluid, as they can readily be eliminated by simple changes in unit policy.

We thank Dr J Jethusathan, Dr J Dave, and the nursing staff of Hammersmith Hospital and the West London Hospital neonatal units for their help with this project.

\section{References \\ I Lorenz JM, Kleinmann LI. Kotagal UR. Reller MD. Water balance in very low birth weight infants: relationship to water and sodium intake and effect on outcome. $J$ Pediatr 1982;101:423-32 \\ 2 Brown ER, Stark A. Sosenko I, Lawson EE, Avery ME. Bronchopulmonary dysplasia: possible relationship to pulmon- ary edema. J Pediatr 1978:92:982-4 \\ 3 Bell EF, Warburton D. Stonestreet BS, Oh W. Effects of fluid administration on the development of symptomatic patent ductus arteriosus and congestive heart failure in premature infants. $N$ Engl J Med 1980;302:598-604.}

Correspondence to Dr C M Noble-Jamieson, 24 Priory Terrace, London NW6 4DH, England.

Received 12 March 1986

\title{
High plasma urea concentrations in collodion babies
}

\author{
D W BEVERLEY AND D WHEELER
}

Bradford Children's Hospital, Bradford, and St James's University Hospital, Leeds

\begin{abstract}
SUMMARY We describe two infants born with a collodion membrane; both were treated with a product containing $10 \%$ urea and $5 \%$ lactic acid and as a consequence were found to have a raised plasma urea concentration.
\end{abstract}

Therapeutic and toxic transdermal absorption of drugs is now well documented. ${ }^{1-6}$ We describe two infants with collodion baby syndrome who developed a high plasma urea concentration during treatment with Calmurid (10\% urea, $5 \%$ lactic acid) when it was used as a skin hydration and keratolytic agent. 


\section{Case reports}

Case 1. This girl was the fifth born child of unrelated Asian parents and weighed $2470 \mathrm{~g}$ at term. The third child in the family had been previously noted to be a collodion baby at birth, to have had lamellar ichthyosis, and to have died as a cot death at the age of 8 months. The index patient had a collodion membrane at birth with pronounced ectropion. For the first few days of life she was treated with simple emollient creams but subsequently Calmurid was applied liberally four times a day for her skin condition. A test for plasma urea concentration was not performed at this time. She required continued treatment with Calmurid as, on shedding the membrane, she was found to have lamellar ichthyosis like her sibling. On day 60 she developed an intercurrent chest infection and was found to have a raised urea concentration on routine testing. On stopping the treatment with Calmurid the plasma urea fell to normal concentrations only to rise again on recommencing treatment. Treatment with Calmurid was therefore stopped (Figure).

Case 2. This first born girl was born to unrelated white parents at 34 weeks' gestation, weighing $2550 \mathrm{~g}$. At birth it was noted that she was coated with a collodion membrane and had short tapering fingers and ectropion. The skin was initially treated with emulsifying ointment and subsequently with Calmurid applied liberally four times a day. After this treatment the membrane began to peel and revealed normal underlying skin. Treatment with

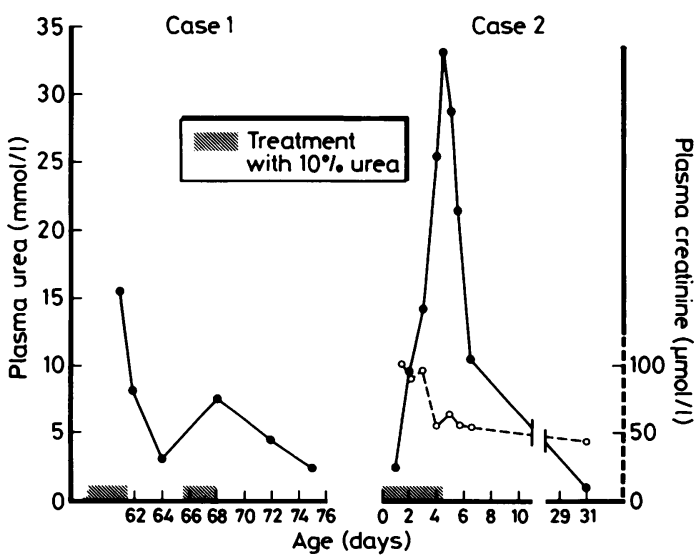

Figure Plasma urea concentrations (1) (cases 1 and 2) and plasma creatinine concentrations $(\mathrm{O})$ (case 2) during the treatment periods with Calmurid (10\% urea, $5 \%$ lactic acid).
Calmurid had to be stopped, however, because of a precipitant rise in the plasma urea concentration despite a normal creatinine concentration (Figure).

Throughout this time the child was clinically hydrated and passed plenty of urine.

\section{Discussion}

We believe that both infants described developed a raised blood urea concentration as a consequence of treatment with the keratolytic agent Calmurid, which contains $10 \%$ urea. It is known that the skin of preterm infants is more permeable than that of the term infant, though this increase in permeability decreases within two to three weeks of birth. ${ }^{1}$ The skin of the term infant is impervious to the absorption of many drugs and in this respect is similar to the skin of adults.

It has been recognised, however, that many substances such as hexachlorophane, ${ }^{2}$ alcohol, ${ }^{3}$ topical corticosteroids, ${ }^{4}$ and iodine ${ }^{5}$ can be absorbed through the skin with toxic effects. Therapeutically, several drugs are now marketed for transdermal use in adults (nitroglycerine, scopolamine, and clonidine), and the percutaneous administration of theophylline in preterm infants with apnoeic spells has recently been described by Evans. ${ }^{6}$

Neither a search of the published reports nor contact with the manufacturers and the Committee of Safety of Medicines have revealed any reports of a high blood urea concentration associated with this product. It is known that the damaged skin of a neonate is more permeable to drugs than normal skin, ${ }^{1}$ which may account for the reasons why our two infants developed a high blood urea concentration. Although we contacted our dermatological colleagues, we were unable to find any other children who were receiving treatment with Calmurid. It would be interesting to know whether this was only a problem of the newborn period or whether it extends into older childhood. The fact that there was a fall in the peak plasma urea concentration with age $(35 \mathrm{mmol} / \mathrm{l}$ on day 2 in case $2,15 \mathrm{mmol} / \mathrm{l}$ on day 60 in case 1) might suggest that transcutaneous absorption of urea becomes less of a problem as the skin matures. This theory would be further supported by the lack of reports of this side effect in the adult studies. We would be interested to hear from other paediatricians to determine the possible extent of this problem. Fortunately, there were no apparent side effects in our two patients, though potentially they could have become dehydrated through an osmotic diuresis. Other side effects of urea include gastric irritation and vomiting when given by mouth and headache, nausea, vomiting, confusion, and a fall in the blood pressure when 
given intravenously. Continued administration may lead to hyponatraemia and hypokalaemia through excessive loss of sodium and potassium.

We report these cases for two reasons; firstly, to re-emphasise the fact that the skin is not a completely impermeable barrier and, secondly, as a reminder that although urea itself is not a particularly toxic substance, other drugs that are used in the treatment of ichthyotic skin conditionsfor example, salicylates and retinoids-are potentially more toxic, especially when absorbed systemically.

We thank Dr D Haigh and Dr P Dear for permission to report their patients.

\section{References}

' Harpin VA. Rutter N. Barrier properties of the newborn infants skin. J Pediatr 1983;102:419-25.
2 Curley A, Hawk RE, Kimbrough RD, Nathenson G, Finberg L. Dermal absorption of hexachlorophane in infants. Lancet 1971;ii:296-7.

${ }^{3}$ Harpin VA. Rutter N. Percutancous alcohol absorption and skin necrosis in premature infants. Arch Dis Child 1982;57:477-9.

4 Fcinblatt BI. Aceto T, Bechom G, Bruck E. Percutaneous absorption of hydrocortisone in children. Am J Dis Child 1966;112:218-23.

5 Chabrolle JP, Rossier A. Goitre and hypothyroidism in the newborn infant after cutancous absorption of iodine. Arch Dis Child 1978;53:495-8.

6 Evans NJ, Rutter N, Hadgraft J, Parr G. Percutaneous admiristration of theophylline in the preterm infant. $J$ Pediatr 1985;107:307-11.

Correspondence to Dr D W Beverley, St James's University Hospital, Leeds, West Yorkshire, England.

Received 17 February 1986
Little is known about actual values of inspired gas humidity during mechanical ventilation of infants. The British Standard recommends as adequate a minimum of $33 \mathrm{mg} \mathrm{H} \mathrm{H}_{2} \mathrm{O} / \mathrm{l}$ of inspired gas in adults and older children receiving ventilatory help.' Previously described methods for measuring gas humidity have included the use of chemical absorptive agents, estimation of dew point, wet and dry bulb thermometry, gravimetry, ${ }^{2}$ and mass spectrometry. ${ }^{3}$ None has proved easy to use in clinical practice. Electronic hygrometry is a recent technique that seems more suitable for clinical use. ${ }^{4}$ We describe the first experience with a small, commercially available, electronic hygrometer in monitoring gas humidity in the proximal airway of mechanically ventilated infants.

\section{Methods}

The device is a battery operated hygrometer (Rotronics Hygroskop GTL, Centronics Sales Ltd, Croydon) measuring $25 \times 6 \mathrm{~cm}$. Temperature is determined by a heat sensitive thermocouple and relative humidity by a capacitive sensor. This is an organic polymer dielectric whose capacitance varies linearly with ambient moisture content between $0-100 \%$ relative humidity. Its response is non-linear in supersaturated atmospheres, tending to overestimate relative humidity above $100 \% .^{4}$

The sensor and thermocouple were most conveniently placed in the patient manifold of the ventilator circuit 3-6 cm distal to the temperature probe of the humidifier. At this site the device estimated the average humidity of inspired and expired gas, not that of inspired gas alone. Absolute humidity was calculated from relative humidity using values of saturated water vapour pressure in standard tables. ${ }^{5}$ No attempt was made to correct for daily variations in atmospheric pressure, the rise in pressure in the circuit due to positive pressure ventilation, or the variation in estimation of relative humidity between air and $100 \%$ oxygen.

Humidity measurements. The humidity sensor was 